\title{
Changes induced by two strains of Vibrio splendidus in haemocyte subpopulations of Mya arenaria, detected by flow cytometry with LysoTracker
}

\author{
Dante R. Mateo ${ }^{1, *}$, Aleks Spurmanis ${ }^{2}$, Ahmed Siah ${ }^{1}$, Mebrahtu T. Araya ${ }^{1}$, \\ Mariana Kulka ${ }^{2}$, Franck C. J. Berthe ${ }^{1,3}$, Gerry R. Johnson ${ }^{1}$, Spencer J. Greenwood ${ }^{1,4}$ \\ ${ }^{1}$ Department of Pathology and Microbiology, Atlantic Veterinary College, University of Prince Edward Island, \\ 550 University Avenue, Charlottetown, Prince Edward Island C1A 4P3, Canada \\ ${ }^{2}$ Institute for Nutrisciences and Health, National Research Council (NRC), Regis and Joan Duffy Research Centre, \\ University of Prince Edward Island, 550 University Avenue, Charlottetown, Prince Edward Island C1A 4P3, Canada \\ ${ }^{3}$ Animal Health and Welfare Unit, European Food Safety Authority (EFSA), Largo N, Palli 5IA, 43100 Parma, Italy \\ ${ }^{4}$ AVC Lobster Science Centre, Atlantic Veterinary College, University of Prince Edward Island, 550 University Avenue, \\ Charlottetown, Prince Edward Island C1A 4P3, Canada
}

\begin{abstract}
Flow-cytometric characterisation of bivalve haemocytes is usually performed by lightscatter profiles based on size and complexity of the cells. Additional means of characterisation such as specific fluorescent dyes are not commonly used to discriminate cell subpopulations in challenged and unchallenged haemocytes. In the present study, we characterise the changes in haemocyte subpopulations of soft-shell clam Mya arenaria induced by in vivo challenge with 2 strains of Vibrio splendidus by using a fluorescent probe. Responses were measured $24 \mathrm{~h}$ after infection with either a local wild strain (7SHRW) or a modification (LGP32-GFP) of a strain associated with oyster mortalities in France (LGP32). Changes in haemocyte subpopulations were analysed using flow cytometry based on 2-parameter scatter profiles and lysosomal content reflected by LysoTracker staining. Forward and side-scatter profiles revealed 2 haemocyte subpopulations: hyalinocytes and granulocytes. Granulocytes exhibited significantly higher levels of lysosomal staining $(\mathrm{p}<0.01)$. Following infection with LGP32-GFP, both subpopulations merged into a single continuous group and their lysosomal content significantly decreased $(p<0.05)$. Independent modifications after infection were observed in the proportions of subpopulations established by their lysosomal content. While the subpopulation of hyalinocytes had lower levels of lysosomal content after infection, especially with LGP32-GFP ( $p<$ 0.001), the subpopulation of granulocytes had similar levels of lysosomes after infection with 7SHRW and significantly decreased levels after infection with LGP32-GFP $(p=0.001)$. Our data suggest specific modulation of bivalve responses against pathogenic bacteria that would include degranulation.
\end{abstract}

KEY WORDS: Mya arenaria · Vibrio splendidus · Haemocyte subpopulations · Flow cytometry • LysoTracker · Lysosome

\section{INTRODUCTION}

Haemocytic ontogeny and typing are undefined aspects of haemocytic characterisation in bivalve molluscs. In the absence of well-defined immunophenotypic markers comparable to those typically employed to study analogous human peripheral blood leucocytes, the characterisation of haemocytic subpopulations in bivalves relies upon morphological features including cell size, complexity or granularity, or functional characteristics including phagocytosis and oxidative burst (Huffman \& Tripp 1982, Cajaraville \& 
Pal 1995, López et al. 1997, Pipe et al. 1997, Cima et al. 2000, Chang et al. 2005, Zhang et al. 2006, Aladaileh et al. 2007, García-García et al. 2008). Interspecies variability and methodological differences in specimen collection and processing have been considered the principal reasons for the current lack of consensus on the actual number of distinct haemocytic subpopulations that can be discerned morphologically (see reviews in Cheng 1981, 1984, Auffret 1988, Hine 1999). There is general agreement, however, that bivalve haemocytes can readily be classified into at least 2 morphologically distinct groups, namely the granulocytes, which tend to be larger and contain cytoplasmic granules, and hyalinocytes (or agranulocytes), which tend to be smaller and contain fewer or no granules.

The cytoplasmic granules that characterise granulocytes are mostly lysosomes, membrane-bound organelles containing hydrolytic enzymes at low $\mathrm{pH}$ (Luzio et al. 2000). In bivalves, haemocyte lysosomes are known to be involved in the intracellular degradation of digestible material and the release of hydrolytic enzymes during phagocytosis in response to infection (reviewed in Cheng 1983). Since their membranes are susceptible to being destabilised by different stressors, this feature has been frequently used as a biomarker to monitor pollution and animal health (reviewed in Moore et al. 2004, 2006).

Since the introduction of flow cytometry to the study of bivalve haemocytes, this tool has gained gradual acceptance due to its practical use and avoidance of subjectivity compared with traditional methods of cell characterisation (Fisher \& Ford 1988, Ashton-Alcox et al. 2000). The application of light-scatter profiling has been used to differentiate bivalve haemocyte subpopulations (Ashton-Alcox \& Ford 1998, Allam et al. 2002, García-García et al. 2008) and to monitor changes in several immune indicators after bacterial challenges (Allam et al. 2001, 2006, Choquet et al. 2003, Lambert et al. 2003, Allam \& Ford 2006, Labreuche et al. 2006). In addition, haemocyte characterisation using fluorescent dyes with affinity to cellular organelles and monoclonal antibodies for specific cellular types conjugated with fluorescent dyes has been used in combination with light-scatter profiles (Renault et al. 2001, Tu et al. 2007).

In soft-shell clams, granulocytes have been successfully discriminated from agranulocytes based on both light-microscopic (Huffman \& Tripp 1982) and flowcytometric analyses (Brousseau et al. 1999, Fournier et al. 2001, 2002). Recently, using flow-cytometric analysis, we reported changes in cell numbers and adhesion of Mya arenaria haemocytes infected with 2 strains of Vibrio splendidus (Mateo et al. 2009). A shift in the distribution of Manila clam Ruditapes philippinarum granulocytes after in vitro challenge with $V$. tapetis has been reported using 2-parameter scatter profiles (Allam \& Ford 2006). Whether bacterial challenge induces changes in the distribution of haemocyte subpopulations of $M$. arenaria is still unknown.

Given its acidic tropism, the commercially available probe LysoTracker has been used to detect lysosomes in studies of human cells (Haller et al. 1996, Via et al. 1998, Blander \& Medzhitov 2004). Here, we report the changes in the distribution of haemocyte subpopulations of Mya arenaria induced by in vivo challenges with 2 strains of Vibrio splendidus using LysoTracker Red. By using this method we supplement light-scatter characterisation of subpopulations of soft-shell clam haemocytes with profiles of cellular lysosomal content.

\section{MATERIALS AND METHODS}

Clams. Wild soft-shell clams Mya arenaria (approximately 4 to $5 \mathrm{~cm}$ in length and $17 \mathrm{~g}$ in weight) shipped from the Centre Maricole des Iles-de-la-Madeleine (CEMIM; Gulf of St. Lawrence, Canada) were used, as they are exposed to minimal levels of pollution. Clams were held in $300 \mathrm{l}$ tanks with recirculating synthetic seawater (Instant Ocean ${ }^{\circledR}$, Aquarium Systems). Throughout the acclimation period clams were fed Spat Formula (Innovative Aquaculture Products) every other day, and water temperature was kept at $16^{\circ} \mathrm{C}$ and salinity at 30 .

Bacteria. Vibrio splendidus LGP32 is a strain associated with mortalities in juvenile oysters Crassostrea gigas in France (Gay et al. 2004a,b), and we used a modified strain (LGP32-GFP) which has a green fluorescence protein (GFP) gene insertion that confers fluorescence through UV light. $V$. splendidus $7 \mathrm{SHRW}$ (GenBank accession no. FJ610758) is a wild strain isolated from sediments from Hillsborough River, Prince Edward Island (Gulf of St. Lawrence, Canada) (Mateo 2006). The identification of this strain as V. splendidus was based on the combination of conventional biochemical tests, BIOLOG automated identification and determination of its $16 \mathrm{~S}$ rDNA sequence, which possesses $98 \%$ similarity to the $16 \mathrm{~S}$ rDNA on chromosome 1 of LGP32 (GenBank accession number FM954972).

Bacterial exponential growth was achieved overnight in trypticase soy broth (TSB; BD-Bacto ${ }^{\mathrm{TM}}$ ) supplemented with $2 \% \mathrm{NaCl}$ at $16^{\circ} \mathrm{C}$. Bacteria were suspended in filtered $(0.22 \mu \mathrm{m})$ sterile seawater (FSSW) after 2 steps of centrifugation $\left(5000 \times g, 16^{\circ} \mathrm{C}, 10 \mathrm{~min}\right)$ and rinsing. Bacterial concentration was adjusted to approximately $3.8 \times 10^{8}$ bacteria $\mathrm{ml}^{-1}$ in FSSW according to 1 optical density $(\mathrm{OD})_{600 \mathrm{~nm}}=4 \times 10^{8}$ bacteria $\mathrm{ml}^{-1}$ as estimated by flow-cytometry cell counting. 
Clam pre-screening and inoculation. In order to avoid using samples from unhealthy or stressed clams, haemolymph was pre-screened through microscopic observation immediately before experiments as previously described (Mateo et al. 2009). Briefly, a drop of haemolymph from each clam was placed on a slide for over 15 min to allow healthy haemocytes to adhere and stretch onto the glass surface. An Axio Imager A1 (Carl Zeiss) light-fluorescent microscope with phase contrast $(\times 400)$ was used to detect bacteria and assess the percentage of rounded haemocytes estimated by calculating the average measurement from 5 different fields. A threshold of $>5 \%$ and/or obvious presence of bacteria were used to exclude unfit animals.

In a total of 21 clams, the posterior adductor muscle was injected with $200 \mu \mathrm{l}$ of either FSSW (control) or 1 of the 2 bacterial suspensions, containing approximately $4.5 \times 10^{6}$ bacteria $\mathrm{g}^{-1}$ of clam. To assure that the bacterial suspension was retained, clams were kept out of the water for $1 \mathrm{~h}$ after injection before transferring them to containers with non-circulating artificial seawater at $16^{\circ} \mathrm{C}$.

Twenty-four hours after infection, haemolymph was withdrawn from the posterior adductor muscle of each clam with a $3 \mathrm{ml}$ syringe fitted with a 25-gauge needle containing $200 \mu \mathrm{l}$ of anti-aggregate Alsever's solution (Sigma). From each clam an aliquot of $400 \mu \mathrm{l}$ of haemolymph was collected and screened through an $80 \mu \mathrm{m}$ mesh to avoid large particles, and immediately placed on ice to prevent formation of haemocyte aggregates.

Morphological profiling. For the analysis of haemocyte subpopulations, $400 \mu \mathrm{l}$ haemolymph samples were treated with LysoTracker ${ }^{\mathrm{TM}}$ Red (Invitrogen-Molecular Probes), a fluorescent probe that stains lysosomes (Fig. 1). A working solution of LysoTracker was prepared by diluting the stock solution 1:1000 in phosphate-buffered saline (PBS) supplemented with $2 \%$ $\mathrm{NaCl}$, and added to $400 \mu \mathrm{l}$ haemolymph samples at a ratio of 1:20. Samples were incubated on ice and in darkness for $2 \mathrm{~h}$, to allow adequate staining prior to analysis in a FACSaria cell sorter (BD Biosciences). PETexas Red channel (600 to $620 \mathrm{~nm}$ ) was used for LysoTracker detection. Excitation was performed with a blue laser (488 $\mathrm{nm}$ ) and the detector PMT voltage was adjusted so that unstained cells appeared in the first decade (i.e. relative fluorescence < 300). The distribution of haemocytes was characterised according to
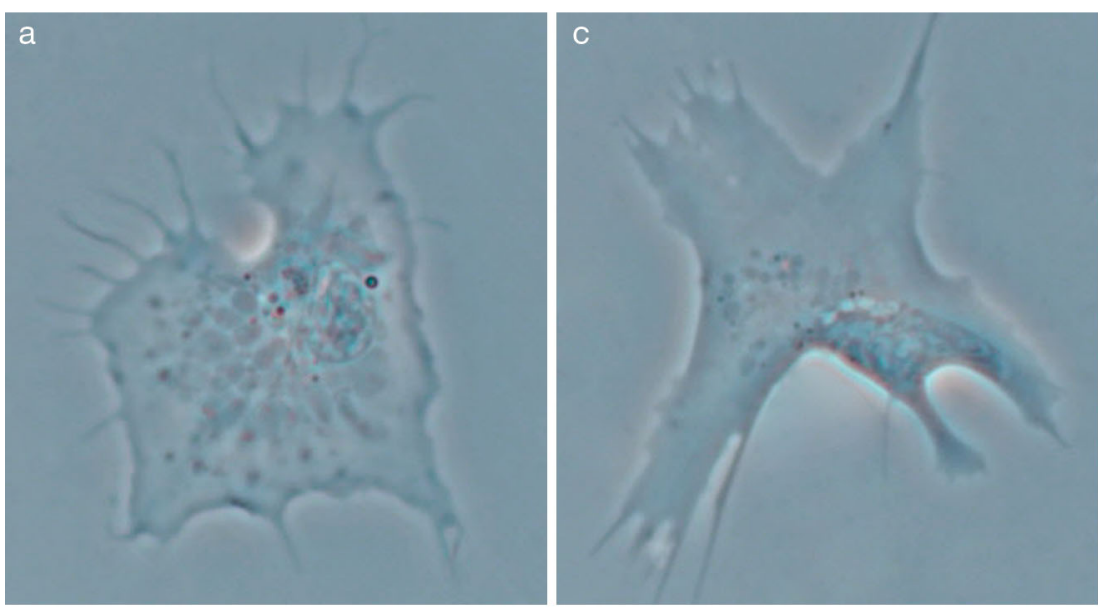

Fig. 1. Mya arenaria haemocytes (×1000). Granulocyte under (a) normal light and (b) fluorescent light showing many lysosomes stained by LysoTracker. Hyalinocyte under (c) normal light and (d) fluorescent light showing a few lysosomes stained by LysoTracker. (e) Rounded cell after infection showing lysosomal content after LysoTracker staining
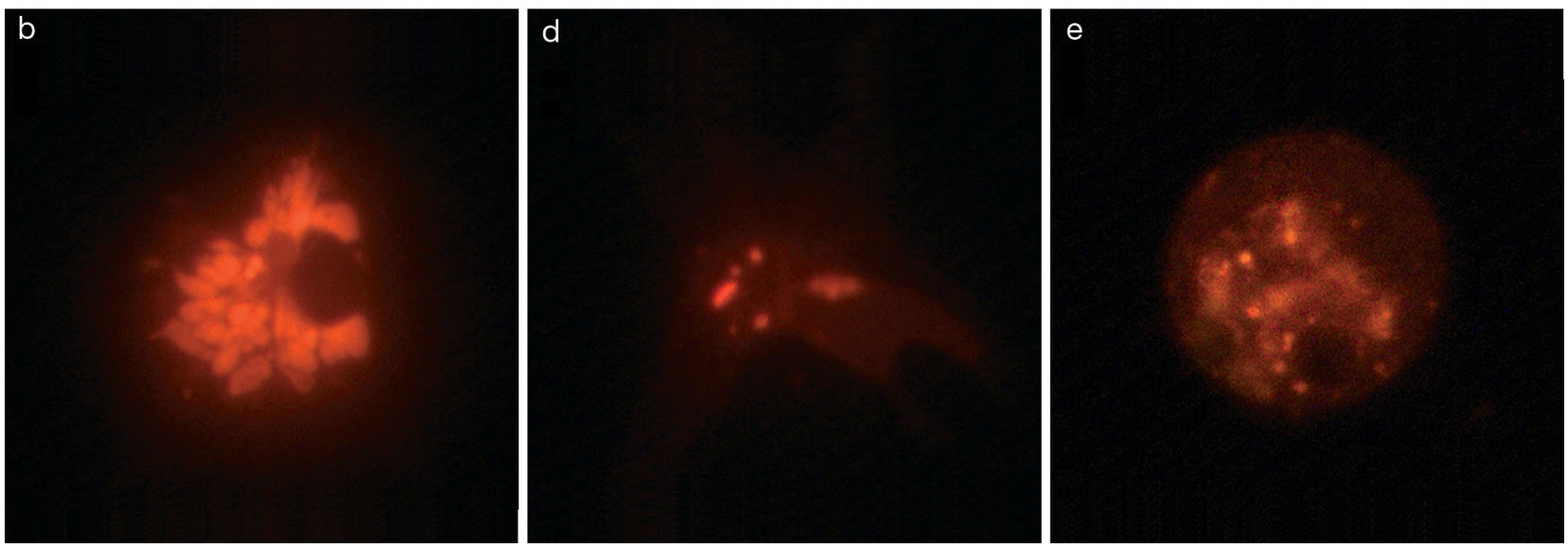
their size and complexity (dependent on the presence of granules and organelles) using 2-parameter scatter profiling: side scatter versus forward scatter. Arbitrary gating was drawn around distinct subpopulations of cells that were readily discernible in healthy specimens. The intensity of fluorescence emitted by LysoTracker was simultaneously measured in a separate fluorescence channel from each gate both before and after infection.

Haemocytes from control and LGP32-GFP-infected clams belonging to each of the subpopulations established by combining the light-scatter and the LysoTracker-staining profiles were physically sorted and immediately fixed with $6 \%$ formalin (prepared with FSSW) for observation by light-fluorescent microscopy under a rhodamine filter. Images were obtained using an Axio Cam imaging system.

Statistical analysis. Statistical analysis was performed using MINITAB 15.1.0.0 statistical software. The differences in fluorescence intensity among haemocyte subpopulations were tested using 1-way general linear ANOVA followed by Bonferroni pairwise comparison to $\log _{10}$-transformed data. The differences in the proportions of haemocytic subpopulations were also tested using ANOVA and Bonferroni pairwise comparison of the arcsine of the square-roottransformed data. When a normal distribution was not achieved, the Kruskal-Wallis nonparametric model was applied followed by the Mann-Whitney test for pairwise comparisons. A statistical significance level of 0.05 was used for differences in all tests.

\section{RESULTS}

Forward versus side-scatter profiles revealed that healthy Mуа arenaria haemocytes were distributed into 2 discernible subpopulations: 1 group (69.1 \pm $23.1 \% \mathrm{SE}$ of the haemocytes) composed of larger and more complex cells, considered to be granulocytes, and another group $(30.9 \pm 3.1 \%$ of the haemocytes $)$ composed of smaller and less complex cells, considered to be hyalinocytes or agranulocytes (Figs. 2 \& 3a). After infection with 7SHRW, the latter subpopulation in the scatter profile became less discernible (Fig. 3b), while with LGP32-GFP infection, both subpopulations appeared to coalesce into a single continuous group (Fig. 3c). When the arbitrary gates established for healthy clam haemocyte subpopulations were maintained, the proportions of these 2 subpopulations did not change significantly after infection with either strain ( $p>0.05$, Figs. $2 \& 3$ ).

Comparison of the median of fluorescent intensity values of LysoTracker staining showed that in control clams, granulocytes exhibited significantly more lyso- somal staining than did hyalinocytes $(p<0.01)$ (Fig. 4). A similar tendency was found after infection with 7SHRW ( $p<0.001)$ and LGP32-GFP $(p<0.001)$. However, the median fluorescence intensity revealed that the lysosomal staining in both haemocyte subpopulations in LGP32-GFP-infected clams was significantly lower than those from control clams $(p<0.01$ for granulocytes, $\mathrm{p}<0.0001$ for hyalinocytes) and from 7SHRW-infected clams $(\mathrm{p}<0.001$ for granulocytes, $\mathrm{p}=$ 0.0001 for hyalinocytes) (Fig. 4).

When each haemocyte subpopulation was further subdivided according to lysosomal content (herein defined as the relative amount of LysoTracker fluorescence observed) into 'low' and 'high' (Fig. 5), the proportions among groups significantly changed after infection, for both hyalinocytes $(\mathrm{p}<0.001)$ and granulocytes $(p=0.001)$ (Fig. 6). Among hyalinocytes, the proportion of cells with high lysosomal content significantly decreased from $85.3 \pm 2.2 \%$ in the control clams to $69.4 \pm 4.7 \%$ in the 7 SHRW-infected clams and to $21.1 \pm 5.4 \%$ in the LGP32-GFP-infected clams (Fig. 6a). Among granulocytes, the proportion of cells with high lysosomal content varied little between the control and the 7SHRW-infected groups, each having $>80 \%$ of cells with high lysosomal content $(87.8 \pm$ $0.4 \%$ and $86.6 \pm 1.8 \%$, respectively) and $<15 \%$ of cells with low lysosomal content $(12.2 \pm 0.4 \%$ and $13.4 \pm$ $1.8 \%$, respectively). These proportions, however, were somewhat inversed in clams infected with LGP32-GFP, with $60.2 \pm 10.6 \%$ of cells having low and $39.8 \pm 10.6 \%$ of cells having high lysosomal content (Fig. 6b).

Microscopic observation of the sorted cells belonging to each of the 4 subpopulations established by the 2-scatter and LysoTracker staining profiles re-

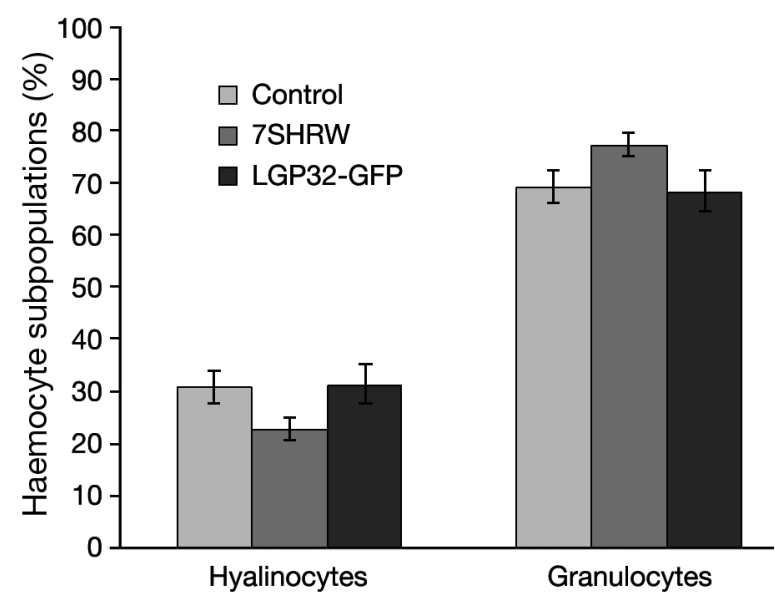

Fig. 2. Mya arenaria haemocytes. Proportions $( \pm \mathrm{SE}$ ) of hyalinocytes and granulocytes from clams $24 \mathrm{~h}$ after injection with filtered sterile seawater (FSSW; control), Vibrio splendidus 7SHRW or $V$. splendidus LGP32-GFP $(\mathrm{n}=21)$. Differences among the treatments were not significant $(p>0.05)$ 

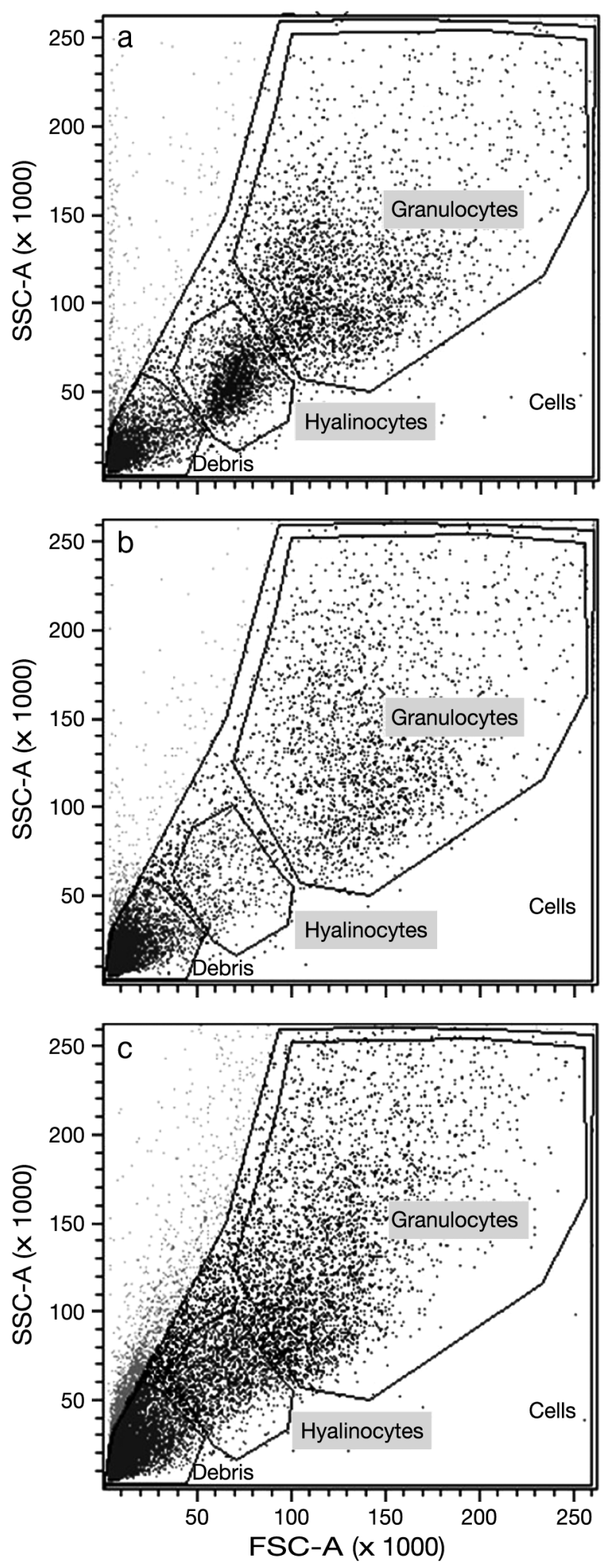

Fig. 3. Mya arenaria haemocyte distribution profile. Forwardscatter (FSC) and side-scatter (SSC) plot profiles of granulocytes and hyalinocytes from clams $24 \mathrm{~h}$ after injection with (a) filtered sterile seawater (FSSW), (b) Vibrio splendidus 7SHRW or (c) V. splendidus LGP32-GFP

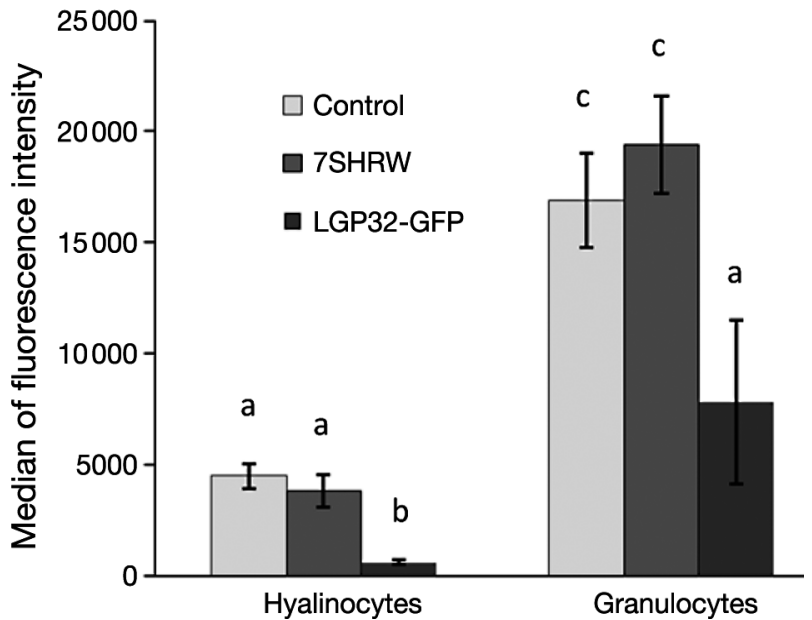

Fig. 4. Mya arenaria haemocytes. Median $( \pm \mathrm{SE})$ fluorescence intensity of LysoTracker retention in granulocytes and hyalinocytes from clams $24 \mathrm{~h}$ after injection with filtered sterile seawater (FSSW; control), Vibrio splendidus 7SHRW or $V$. splendidus LGP32-GFP ( $\mathrm{n}=21)$. Letters show statistical equivalence (same letters) or difference at $\mathrm{p}<0.05$ (different letters) between pairs of haemocyte subpopulations and treatments

vealed cells of different sizes and cytoplasm content (Fig. 7). Hyalinocytes had a diameter of approximately 5 to $7 \mu \mathrm{m}$ (Fig. $7 \mathrm{a}, \mathrm{b}, \mathrm{e}, \mathrm{f})$ whereas in granulocytes it was around 9 to $13 \mu \mathrm{m}$ (Fig. $7 \mathrm{c}, \mathrm{d}, \mathrm{g}, \mathrm{h}$ ). Haemocytes sorted from the 'high' LysoTracker staining subpopulation (Fig. $7 \mathrm{~b}, \mathrm{~d}, \mathrm{f}, \mathrm{h}$ ) appeared to have a higher granularity compared with those with 'low' staining (Fig. $7 \mathrm{a}, \mathrm{c}, \mathrm{e}, \mathrm{g}$ ). To some extent, the cytoplasm content of the control haemocytes appeared to be homogeneously distributed, while in LGP32-GFP-infected cells it appeared to be localised towards one side of the cell and the nucleus was often indistinguishable.

\section{DISCUSSION}

Flow cytometry is a useful technique for the characterisation of haemocyte subpopulations in bivalves. Analyses using these methods are mostly based on 2side scatter profiles that delineate subpopulations according to cell size and complexity. Additional fluorescent dyes can be used to reveal complementary information about cellular components for a more complete characterisation. In the present study, the use of LysoTracker, as an indicator of lysosomal content, in addition to light-scatter profiles, revealed different haemocyte subpopulations in Mya arenaria. These subpopulations were shown to undergo changes in proportions that suggest interesting cellular processes induced by 2 strains of Vibrio splendidus, a local wild 


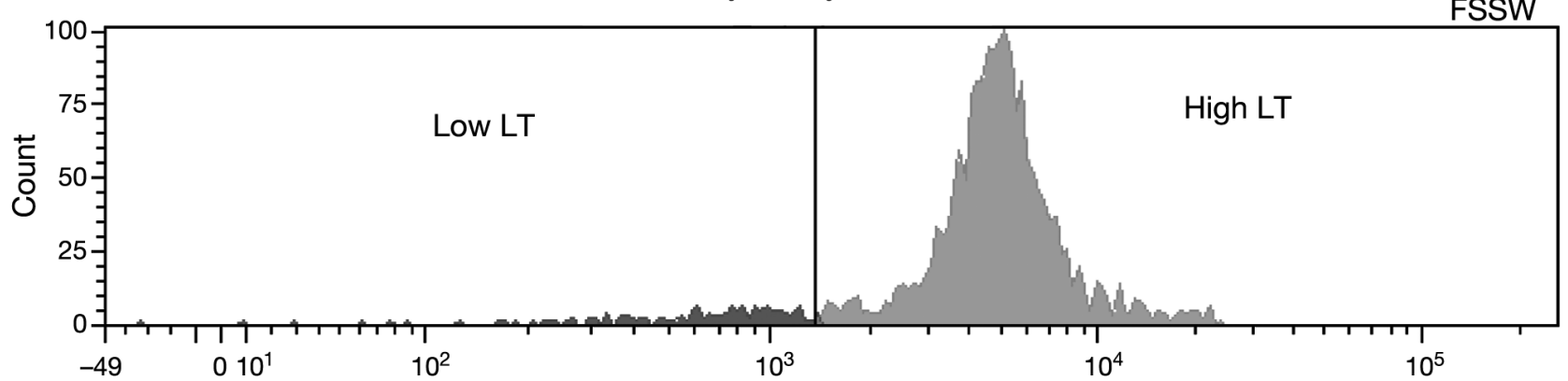

7SHRW
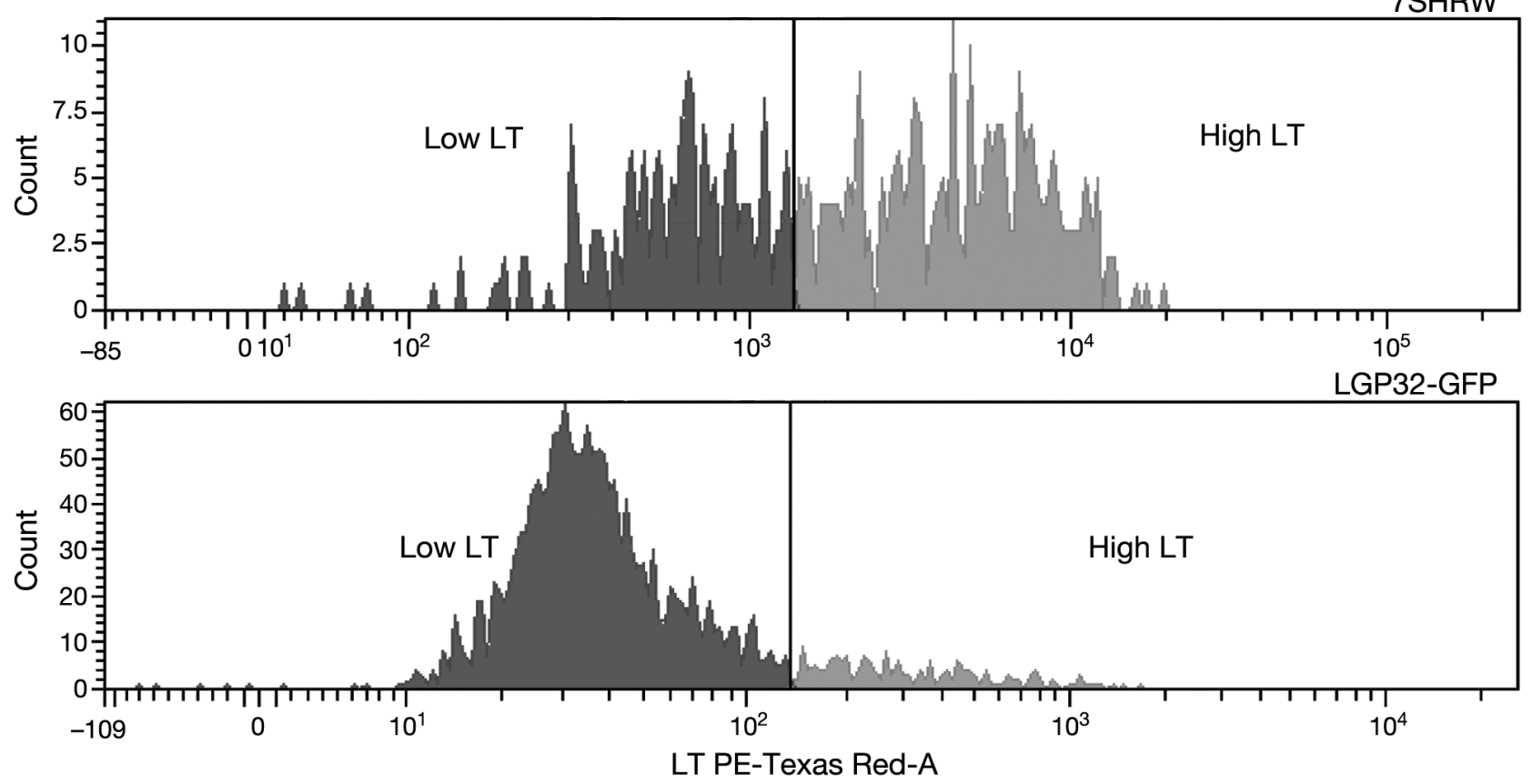

Fig. 5. Mya arenaria haemocytes with LysoTracker. Median fluorescence intensity of LysoTracker (LT) retention (arbitrarily established as 'high' and 'low') in (a) hyalinocytes and (b) granulocytes from clams $24 \mathrm{~h}$ after injection with filtered sterile seawater (FSSW; top), Vibrio splendidus 7SHRW (middle) or V. splendidus LGP32-GFP (bottom)

strain and a strain associated with oyster mortalities in France.

Through the flow-cytometry scatter profiles (forward and side-scatter) we observed 2 discernible subpopulations of haemocytes in Mya arenaria: a discrete subpopulation of smaller and less complex cells and another, more dispersed, subpopulation of larger and more complex cells. We think that the former subpopulation was composed of hyalinocytes and/or agranulocytes (with no or few cytoplasmic granules) and the latter, granulocytes. This latter subpopulation might include what others have classified as small and large granulocytes (reviewed in Cheng 1981). Previously, using flow-cytometric toxicological studies of $M$. arenaria haemocytes, 2 discernible subpopulations using 2-scatter profiles were also noticed (Brousseau et al. 1999, Fournier et al. 2001, 2002).
Prior reports involving flow-cytometric light-scatter profiling revealed that haemocytes from a number of bivalve species can typically be classified into 2, 3 or 4 subpopulations. Haemocytes from clams Ruditapes philippinarum, $R$. decussatus and Mercenaria mercenaria have been classified into 2 subpopulations: hyalinocytes and granulocytes, located in the lower and higher channels of both light-scatter axes, respectively (Allam et al. 2001, 2002, 2006, Allam \& Ford 2006). In the scallop Chlamys farreri, 2 haemocyte types have been identified: granulocytes and hyalinocytes (Xing et al. 2002). The hard clam Meretrix lusoria has been reported to have 3 subpopulations: hyalinocytes and small and large granulocytes (Tu et al. 2007). In mussels Mytilus galloprovincialis, 3 subpopulations (hyalinocytes and small and large granulocytes) (Parisi et al. 2008) and 4 subpopulations (large granu- 
b

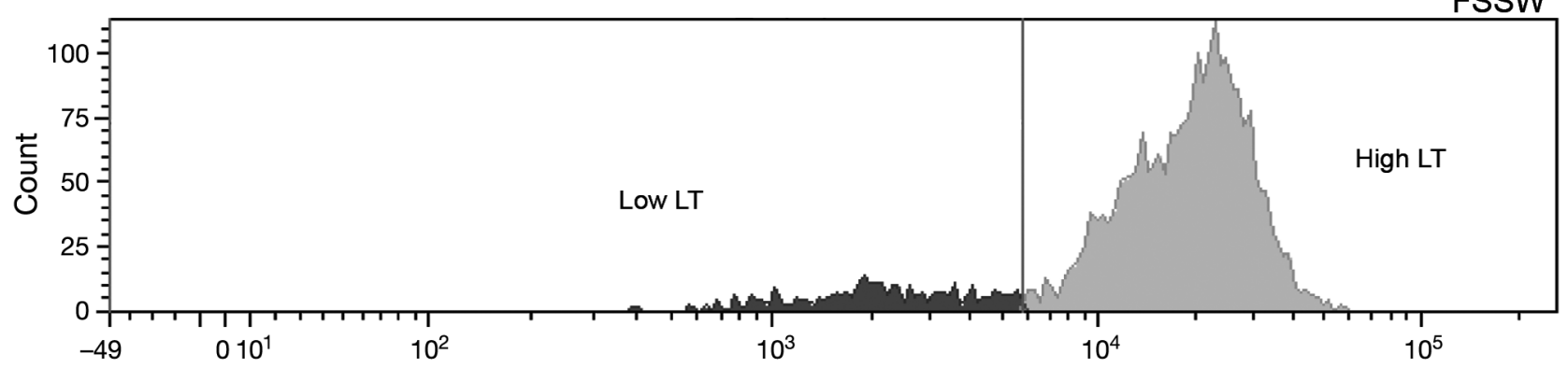

7SHRW
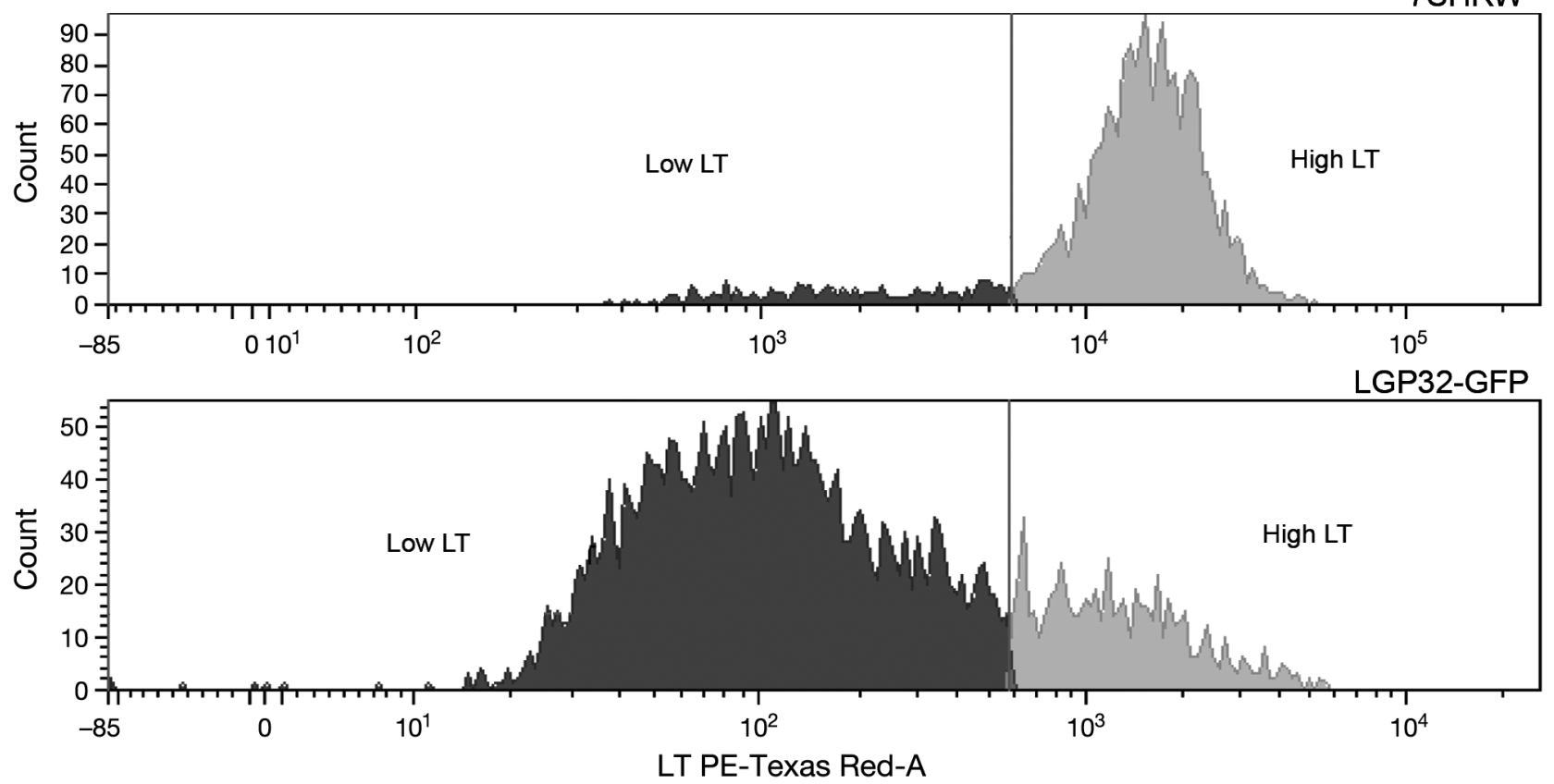

Fig. 5 (continued)

locytes, large semigranulocytes, smaller granulocytes and small agranulocytes or hyalinocytes) (García-García et al. 2008) have been considered. Oysters Crassostrea virginica and C. gigas were shown to possess 3 haemocyte subpopulations, although they were regarded slightly differently by different researchers (Ashton-Alcox \& Ford 1998, Allam et al. 2002, Lambert et al. 2003, Goedken \& De Guise 2004). In the Sydney rock oyster Saccostrea glomerata, up to 4 subpopulations were distinguished, although hyalinocytes and granulocytes were the 2 most abundant phenotypes (Aladaileh et al. 2007).

Following infection with Vibrio splendidus 7SHRW, the proportion of hyalinocytes slightly decreased (Fig. 2) and became less discernible in the scatter profile (Fig. 3b), while with the strain LGP32-GFP, changes were more striking, as both subpopulations merged into a single continuous group (Fig. 3c). Drastic changes in haemocyte distribution according to size and granularity have been previously noticed by Allam
\& Ford (2006). They observed a clear shift of granular cells towards the agranular cell population, resulting in unimodal distribution of haemocytes from clams Ruditapes philippinarum and Mercenaria mercenaria after in vitro exposure to $V$. tapetis and $V$. splendidus.

We supplemented our light-scatter profiling data with LysoTracker staining in order to provide a measure of lysosome content. LysoTracker is a fluorescent probe that accumulates in acidic compartments (Freundt et al. 2007) and has been used previously in studies of human-cell lysosomes (Haller et al. 1996, Via et al. 1998, Blander \& Medzhitov 2004). This approach, applied for the first time to bivalve haemocytes in the present study, revealed independent responses in haemocyte subpopulations (Figs. 4, 5 \& 6). LysoTracker staining showed that granulocytes from the control clams contained significantly more lysosomes than the hyalinocytes. This is in agreement with microscopic observations, and indirectly with enzyme studies, which have shown that granulocytes have abundant 

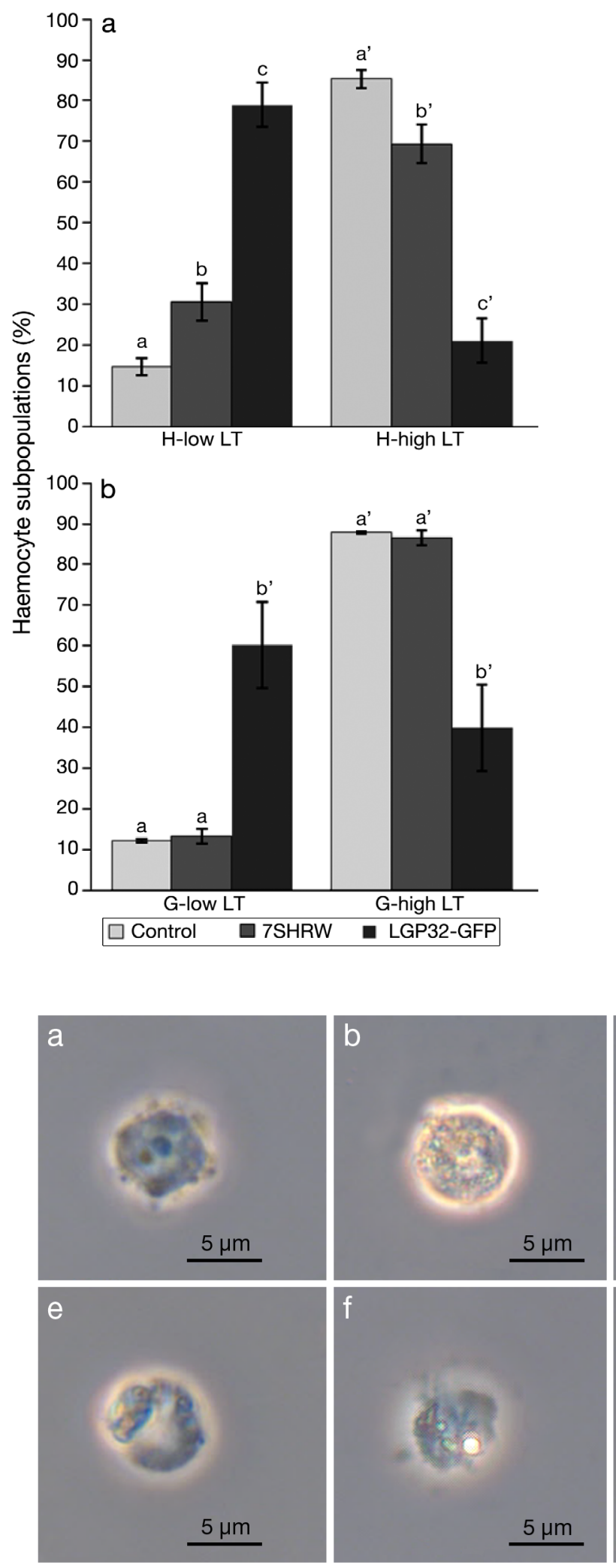

Fig. 6. Mya arenaria haemocyte subpopulations. Proportion $( \pm \mathrm{SE})$ that are (a) hyalinocytes $(\mathrm{H})$ or $(\mathrm{b})$ granulocytes $(\mathrm{G})$ according to LysoTracker (LT; 'high' or 'low') staining $24 \mathrm{~h}$ after injection of clams with filtered sterile seawater (FSSW; control), Vibrio splendidus 7SHRW or $V$. splendidus LGP32-GFP $(\mathrm{n}=21)$. Letters show statistical equivalence (same letters) or difference at $\mathrm{p}<0.05$ (different letters) among treatments

lysosomes (Pipe 1990, Cajaraville \& Pal 1995, Cima et al. 2000, Matozzo et al. 2007).

When challenged bacterially, hyalinocytes had lower levels of lysosomal content, especially after infection with LGP32-GFP (Figs. 4, 5a \& 6a), whereas granulocytes had similar levels of lysosomes after infection with 7SHRW and significantly decreased levels after infection with LGP32-GFP (Figs. 4, 5b \& $6 b)$. Lysosomes are cellular organelles that contain hydrolytic enzymes (Luzio et al. 2000), including lysozymes, that are involved in intracellular degradation and host defence (Olsen et al. 2003). Many lysosomes have secretory functions (Holt et al. 2006). Similar to mammalian macrophages, in several bivalves including Муа arenaria, lysosomes release their content upon infection during degranulation of actively phagocytosing cells (Cheng \& Rodrick 1974, Rodrick 1979; reviewed in Cheng 1983, Chu 1988). Lysosomal degranulation may be one possible mechanism accounting for the decrease of lysosomal content, expressed as loss of fluorescent intensity (Figs. 4 \& 5) and change in proportions (Fig. 6) in haemocytes from Vibrio splendidus LGP32-GFP-infected clams.
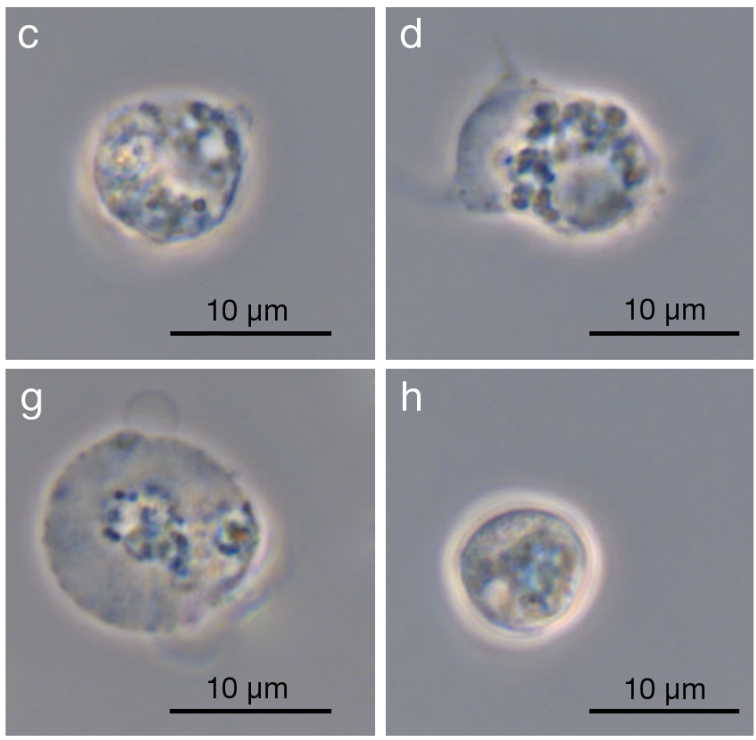

Fig. 7. Mya arenaria haemocytes. Phase-contrast images of immediately fixed haemocytes from each subpopulation. Control group: hyalinocytes with (a) 'low' and (b) 'high' LysoTracker staining; granulocytes with (c) 'low' and (d) 'high' LysoTracker staining. Vibrio splendidus LGP32-GFP-infected group: hyalinocytes with (e) 'low' and (f) 'high' LysoTracker staining; granulocytes with (g) 'low' and (h) 'high' LysoTracker staining 
The decreased responsiveness to $V$. splendidus 7SHRW insult could, by extension, be attributable to a decreased capacity to activate degranulation in Mya arenaria haemocytes.

Considering that 7SHRW is a wild endemic strain isolated from sediments from an area relatively close to the source area of our clams, where there is no history of bacterial infections, this strain may be recognised by the haemocyte's pattern-recognition receptors as a non-threat, non-self particle. On the other hand, LGP32 is a non-native strain that has been associated with mortalities of juvenile Pacific oysters Crassostrea gigas in Europe (Gay et al. 2004a,b). Moreover, it has been found that this strain possesses the pathogenic factor vsm, a metalloprotease recently demonstrated to be the most important toxicity factor in the extracellular products of LGP32 (Binesse et al. 2008). It is likely that this pathogenic factor is associated with the significant degranulation of Mya arenaria haemocytes in the present study. The specific response of $M$. arenaria haemocytes to the strain LGP32-GFP is in accordance with our previous findings that this strain induces significant changes in haemocyte structure, number and adhesion on this host species, whereas changes induced by 7SHRW are minor or nonexistent (Mateo et al. 2009).

The decrease in lysosomal content in hyalinocytes (Figs. $4 \& 5 b$ ) or the increase of hyalinocytes with low levels of lysosomal content (Figs. 5a \& 6a) might not only be due to degranulation but possibly due to the increased presence of precursor haemocytes that have not yet developed cytoplasmic granules. They might be released prematurely to fight the infection. A similar phenomenon, known as 'left shift', occurs in mammalian leucocytes upon inflammation and septic shock (Opdenakker 2001). Undifferentiated and small stem cells have been described as blast-like cells or haemoblasts, a subtype of agranular cells with a high nucleus:cytoplasm ratio and which lack organelles (Hine 1999, Cima et al. 2000, Chang et al. 2005, Aladaileh et al. 2007, Matozzo et al. 2008). Further research is, however, required to confirm the nature of the abundant smaller and less complex cells we found after Vibrio splendidus LGP32-GFP challenge.

In conclusion, we found that responses of haemocytic subpopulations are not only specific to the pathogen strain, but are modulated independently of each other and possibly through independent cellular mechanisms. These changes in haemocytic subpopulations were monitored by using LysoTracker as an indicator of the lysosomal content, and more striking responses were found after infection with Vibrio splendidus LGP32-GFP. Functional studies are needed to confirm the activation of degranulation and the suspected release of immature haemocytes.
Acknowledgements. We acknowledge the kind support of Dr. F. Le Roux (Harvard Medical School, formerly at Institut Pasteur) for providing the bacterial strain LGP32-GFP and of L. Chevarie (Centre Maricole des Iles-de-la-Madeleine, CEMIM) for providing the clams. This work was funded by the Industrial Research Assistance Program (IRAP), the Natural Sciences and Engineering Research Council of Canada (NSERC) and Technology PEI. D.R.M. is supported by a PhD scholarship from AVC.

\section{LITERATURE CITED}

Aladaileh S, Nair SV, Birch D, Raftos DA (2007) Sydney rock oyster (Saccostrea glomerata) haemocytes: morphology and function. J Invertebr Pathol 96:48-63

Allam B, Ford SE (2006) Effects of the pathogenic Vibrio tapetis on defence factors of susceptible and non-susceptible bivalve species: I. Haemocyte changes following in vitro challenge. Fish Shellfish Immunol 20:374-383

Allam B, Ashton-Alcox KA, Ford SE (2001) Haemocyte parameters associated with resistance to brown ring disease in Ruditapes spp. clams. Dev Comp Immunol 25:365-375

Allam B, Ashton-Alcox KA, Ford SE (2002) Flow cytometric comparison of haemocytes from three species of bivalve molluscs. Fish Shellfish Immunol 13:141-158

Allam B, Paillard C, Auffret M, Ford S (2006) Effects of the pathogenic Vibrio tapetis on defence factors of the susceptible and non-susceptible bivalve species: II. Cellular and biochemical changes following in vivo challenge. Fish Shellfish Immunol 20:384-397

> Ashton-Alcox KA, Ford SE (1998) Variability in molluscan hemocytes: a flow cytometric study. Tissue Cell 30:195-204

Ashton-Alcox KA, Allam B, Ford SE (2000) Application of flow cytometry to bivalve pathology. In: Fingerman M, Nagabhushanam R (eds) Recent advances in marine biotechnology. Science Publishers, Enfield, NH, p 85-124

Auffret M (1988) Bivalve hemocyte morphology. Am Fish Soc Spec Publ 18:169-177

Binesse J, Delsert C, Saulnier D, Champomier-Vergès MC and others (2008) Metalloprotease vsm is the major determinant of toxicity for extracellular products of Vibrio splendidus. Appl Environ Microbiol 74:7108-7117

Blander JM, Medzhitov R (2004) Regulation of phagosome maturation by signals from Toll-like receptors. Science 304:1014-1018

Brousseau P, Pellerin J, Morin Y, Cyr D, Blakley B, Boermans $\mathrm{H}$, Fournier M (1999) Flow cytometry as a tool to monitor the disturbance of phagocytosis in the clam Mya arenaria hemocytes following in vitro exposure to heavy metals. Toxicology 142:145-156

Cajaraville MP, Pal SG (1995) Morphofunctional study of the haemocytes of the bivalve mollusc Mytilus galloprovincialis with emphasis on the endolysosomal compartment. Cell Struct Funct 20:355-367

Chang SJ, Tseng SM, Chou HY (2005) Morphological characterization via light and electron microscopy of the haemocytes of two cultured bivalves: a comparison study between the hard clam (Meretrix lusoria) and Pacific oyster (Crassostrea gigas). Zool Stud 44:144-153

Cheng TC (1981) Bivalves. In: Ratcliffe NA, Rowley AF (eds) Invertebrate blood cells, Vol I. Academic Press, London, p 233-300

Cheng TC (1983) The role of lysosomes in molluscan inflammation. Am Zool 23:119-144

Cheng TC (1984) A classification of molluscan haemocytes based on functional evidence. In: Bulla LA, Cheng TC 
(eds) Comparative pathobiology, Vol 6. Plenum Press, New York, p 111-146

Cheng TC, Rodrick GE (1974) Identification and characterization of lysozyme from hemolymph of the soft-shelled clam, Mya arenaria. Biol Bull (Woods Hole) 147:311-320

Choquet G, Soudant P, Lambert C, Nicolas JL, Paillard C (2003) Reduction of adhesion properties of Ruditapes philippinarum haemocytes exposed to Vibrio tapetis. Dis Aquat Org 57:109-116

Chu FLE (1988) Humoral defense factors in marine bivalves. Am Fish Soc Spec Publ 18:178-188

Cima F, Matozzo V, Marin MG, Ballarin L (2000) Haemocytes of the clam Tapes philippinarum (Adams \& Reeve, 1850): morphofunctional characterisation. Fish Shellfish Immunol 10:677-693

Fisher WS, Ford SE (1988) Flow cytometry: a tool for cell research in bivalve pathology. Am Fish Soc Spec Publ 18: 286-291

Fournier M, Pellerin J, Clermont Y, Morin Y, Brousseau P (2001) Effects of in vivo exposure of Mya arenaria to organic and inorganic mercury on phagocytic activity of hemocytes. Toxicology 161:201-211

> Fournier M, Pellerin J, Lebeuf M, Brousseau P, Morin Y, Cyr D (2002) Effects of exposure of Mya arenaria and Mactromeris polynyma to contaminated marine sediments on phagocytic activity of haemocytes. Aquat Toxicol 59:83-92

Freundt EC, Czapiga M, Lenardo MJ (2007) Photoconversion of Lysotracker Red to a green fluorescent molecule. Cell Res 17:956-958

- García-García E, Prado-Álaverz M, Novoa B, Figueras A, Rosales C (2008) Immune responses of mussel hemocyte subpopulations are differentially regulated by enzymes of the PI 3-K, PKC, and ERK kinase families. Dev Comp Immunol 32:637-653

Gay M, Berthe F, Le Roux F (2004a) Screening of Vibrio isolates to develop an experimental infection model in the Pacific oyster Crassostrea gigas. Dis Aquat Org 59:49-56

Gay M, Renault T, Pons AM, Le Roux F (2004b) Two Vibrio splendidus related strains collaborate to kill Crassostrea gigas: taxonomy and host alterations. Dis Aquat Org 62: $65-74$

Goedken M, De Guise S (2004) Flow cytometry as a tool to quantify oyster defence mechanisms. Fish Shellfish Immunol 16:539-552

Haller T, Dietl P, Deetjen P, Völkl H (1996) The lysosomal compartment as intracellular calcium store in MDCK cells: a possible involvement in $\mathrm{InsP}_{3}$-mediated $\mathrm{Ca}^{2+}$ release. Cell Calcium 19:157-165

Hine PM (1999) The inter-relationship of bivalve haemocytes. Fish Shellfish Immunol 9:367-385

Holt OJ, Gallo F, Griffiths GM (2006) Regulating secretory lysosomes. J Biochem 140:7-12

- Huffman JE, Tripp MR (1982) Cell types and hydrolytic enzymes of soft shell clam (Mya arenaria) haemocytes. J Invertebr Pathol 40:68-74

Labreuche Y, Lambert C, Soudant P, Boulo V, Huvet A, Nicolas JL (2006) Cellular and molecular hemocyte response of the Pacific oyster, Crassostrea gigas, following bacterial infection with Vibrio aestuarianus strain 01/32. Microbes Infect 8:2715-2724

- Lambert C, Soudant P, Choquet G, Paillard C (2003) Measurement of Crassostrea gigas hemocyte oxidative metabolism by flow cytometry and the inhibiting capacity of pathogenic vibrios. Fish Shellfish Immunol 15:225-240

López C, Carballal MJ, Azevedo C, Villalba A (1997) Morphological characterization of the hemocytes of the clam,
Ruditapes decussates (Mollusca: Bivalvia). J Invertebr Pathol 69:51-57

Luzio JP, Pryor PR, Bright NA (2000) Lysosome-endosome fusion and lysosomes biogenesis. J Cell Sci 113:1515-1524

Mateo DR (2006) Assessment of antimicrobial resistance in marine environments of Prince Edward Island using a selected bacterial group. MSc dissertation, Atlantic Veterinary College, University of Prince Edward Island, Charlottetown, PEI

Mateo DR, Siah A, Araya MT, Berthe FCJ, Johnson GR, Greenwood SJ (2009) Differential in vivo response of softshell clam hemocytes against two strains of Vibrio splendidus: changes in cell structure, numbers and adherence. J Invertebr Pathol 102:50-56

- Matozzo V, Rova G, Marin MG (2007) Haemocytes of the cockle Ceratoderma glaucum: morphological characterisation and involvement in immune responses. Fish Shellfish Immunol 23:732-746

Matozzo V, Marin MG, Cima F, Ballarin L (2008) First evidence of cell division in circulating haemocytes from the Manila clam Tapes philippinarum. Cell Biol Int 32: 865-868

> Moore MN, Depledge MH, Readman JW, Leonard DRP (2004) An integrated biomarker-based strategy for ecotoxicological evaluation of risk in environmental management. Mutat Res 552:247-268

> Moore MN, Allen JI, McVeigh A (2006) Environmental prognostics: an integrated model supporting lysosomal stress responses as predictive biomarkers of animal health status. Mar Environ Res 61:278-304

Olsen ØM, Nilsen IW, Sletten K, Myrnes B (2003) Multiple invertebrate lysozymes in blue mussel (Mytilus edulis). Comp Biochem Physiol B 136:107-115

> Opdenakker G (2001) New insights in the regulation of leukocytosis and the role played by leukocytes in septic shock. Verh K Acad Geneeskd Belg 63:531-538

Parisi MG, Li H, Jouvet LBP, Dyrinda EA, Parrinello N, Cammarata M, Roch P (2008) Differential involvement of mussel hemocyte sub-populations in the clearance of bacteria. Fish Shellfish Immunol 25:834-840

> Pipe RK (1990) Hydrolytic enzymes associated with the granular haemocytes of the marine mussel Mytilus edulis. Histochem J 22:595-603

Pipe RK, Farley SR, Coles JA (1997) The separation and characterisation of haemocytes from the mussel Mytilus edulis. Cell Tissue Res 289:537-545

> Renault T, Xue QG, Chilmonczyk S (2001) Flow cytometric analysis of European flat oyster, Ostrea edulis, haemocytes using a monoclonal antibody specific for granulocytes. Fish Shellfish Immunol 11:269-274

Rodrick GE (1979) Selected enzyme activities in Mya arenaria hemolymph. Comp Biochem Physiol B 62:313-316

Tu CY, Hung SW, Tsou LT, Chang YC, Wang WS (2007) Simultaneous flow cytometry assessment for cellular types and phagocytic abilities of the haemocytes of the hard clam, Meretrix lusoria. Fish Shellfish Immunol 23: $16-23$

Via LE, Fratti RA, McFalone M, Pagán-Ramos E, Deretic D, Deretic V (1998) Effects of cytokines on mycobacterial phagosome maturation. J Cell Sci 111:897-905

> Xing J, Zhan WB, Zhou L (2002) Endoenzymes associated with haemocyte types in the scallop (Chlamys farreri). Fish Shellfish Immunol 13:271-278

- Zhang W, Wu X, Wang M (2006) Morphological, structural, and functional characterization of the haemocytes of the scallop, Argopecten irradians. Aquaculture 251:19-32 